\title{
Educação e trabalho na percepção de estudantes do Curso de Agronomia do Instituto Federal de Santa Catarina, campus São Miguel do Oeste: aproximações, diagnósticos e desafios.
}

\section{Education and work on the perception of students of the Agronomy course at the Federal Institute of Santa Catarina, campus São Miguel do Oeste: approaches, diagnoses and challenges.}

\section{Educación y trabajo desde la percepción de los estudiantes de la carrera de Agronomía del Instituto Federal de Santa Catarina, campus São Miguel do Oeste: acercamientos, diagnósticos y desafíos.}

\author{
Mascarelo, Idianes Tereza ${ }^{1}$ (São Miguel do Oeste, SC, Brasil) \\ ORCID ID: https://orcid.org/0000-0003-4678-1271 \\ Dentz, Volmir von ${ }^{2}$ (São José, SC, Brasil) \\ ORCID ID: https://orcid.org/0000-0002-6139-0909
}

\section{Resumo}

Este artigo apresenta uma pesquisa que foi realizada com o objetivo de identificar a percepção dos alunos do $8^{\circ}$ período do curso de Agronomia do Instituto Federal de Santa Catarina (IFSC), campus de São Miguel do Oeste, quanto à educação e ao mundo do trabalho. As discussões estão alicerçadas principalmente nas produções teóricas de autores de referência na temática "educação e trabalho": Dermeval Saviani, na questão do princípio educativo do trabalho; Ricardo Antunes, quanto aos sentidos dados ao trabalho no mundo contemporâneo; e Sérgio Lessa, sobre as realizações humanas mediante o trabalho. Assim, o texto contempla considerações sobre: os desafios contemporâneos do mundo do trabalho, os impactos da educação na vida profissional dos educandos e a análise das reflexões acerca dos conceitos de trabalho como princípio educativo. As percepções dos alunos foram discutidas com base em duas categorias principais: o perfil dos estudantes do referido curso e a relação que estabelecem entre a educação e o mundo do trabalho. O estudo traz elementos que contribuem para repensar a práxis educativa e seu compromisso com a formação dos trabalhadores, no sentido da reflexão apresentada sobre o conceito de trabalho como princípio político-educativo numa perspectiva emancipadora do ser humano.

Palavras-chave: Curso de agronomia. Educação profissional e tecnológica. Práxis. Trabalho.

\begin{abstract}
This article presents a research that was carried out to identify the perception of students of the 8th period of the Agronomy course at the Federal Institute of Santa Catarina (IFSC), campus São Miguel do Oeste, regarding education and work. The discussions are based mainly on the theoretical productions of leading authors on the theme "education and work": Dermeval Saviani, on the issue of the educational principle of work, Ricardo Antunes, regarding the meanings given to work in the contemporary world, and Sérgio Lessa, on human achievements through work. Thus, the text includes considerations about contemporary challenges in the world of work, the impacts of education on the students' professional lives, and the analysis of reflections about the concepts of work as an educational principle. The students' perceptions were discussed based on two main categories: the profile of the students of that course and the relationship they establish between education and the world of work. The study shows elements that contribute to thinking educational praxis and its commitment to the qualification of workers, in the sense of the reflection presented on the concept of work as a political-educational principle in an emancipatory perspective of the human being.
\end{abstract}

Keywords: Agronomy course. Professional and technological education. Praxis. Work.

\footnotetext{
1 Pedagoga no Instituto Federal de Santa Catarina, campus de São Miguel do Oeste (IFSC-SMO), idianes.mascarelo@ifsc.edu.br.

2 Professor do Instituto Federal de Santa Catarina, campus de São José (IFSC-SJ), vinculado à Área de Cultura
} Geral (COGER). volmirvon@gmail.com. 


\begin{abstract}
Resumen
Este artículo resulta de una investigación que se ha realizado con el objetivo de identificar la percepción de alumnos del $8^{\circ}$ semestre de la carrera de Agronomía del Instituto Federal de Santa Catarina (IFSC), campus São Miguel do Oeste, acerca de la educación y del universo laboral. Las discusiones se han basado sobretodo en el aporte teórico de autores expertos en el tema "educación y trabajo": Dermeval Saviani, en la cuestión del principio educativo del trabajo, Ricardo Antunes, en lo que toca a los sentidos dados al trabajo en el mundo contemporáneo, y Sérgio Lessa en el tema de las realizaciones humanas por el trabajo. El texto trae entonces reflexiones acerca de los desafíos contemporáneos del mundo laboral, de los impactos de la educación en la vida profesional de los alumnos y el análisis de las reflexiones sobre los conceptos de trabajo como principio educativo. Las percepciones de los alumnos fueron discutidas considerando dos categorias: el perfil de los estudiantes de esta carrera (Agronomía) y la relación que construyen entre educación y mundo laboral. El estudio aporta elementos que contribuyen para repensar la praxis educativa y su compromiso con la formación de trabajadores por su reflexión acerca del concepto de trabajo como principio político-educativo desde una perspectiva emancipadora del ser humano.
\end{abstract}

Palabras clave: Carrera de Agronomía. Educación profesional y tecnológica. Praxis. Trabajo.

\title{
Introdução
}

A análise das relações entre trabalho e educação torna-se essencial quando se trata dos objetivos do Instituto Federal de Santa Catarina (IFSC), e particularmente no que se refere ao campus de São Miguel do Oeste (SMO), pois, considerando as diferentes formações oportunizadas pela instituição, pode-se afirmar que possui compromisso com o mundo do trabalho e com a educação profissional. Isso é evidenciado pela finalidade descrita no Plano de Desenvolvimento Institucional:

ofertar educação profissional e tecnológica em todos os níveis e modalidades, formando e qualificando cidadãos com vistas à atuação profissional nos diversos setores da economia, com ênfase no desenvolvimento socioeconômico local, regional e nacional (IFSC, 2014, p. 8).

A formação para o exercício da profissão é marcada significativamente pelo ensino que os educandos recebem na instituição. Nesse sentido, discutir a formação integral dos sujeitos implica pensar nas relações entre a educação propedêutica e o mundo do trabalho. Sabe-se que os processos produtivos e os ambientes organizacionais estão alicerçados nas premissas do mundo do trabalho e nas metamorfoses características da intensificação da exploração, em um mercado cada vez mais competitivo, que têm efeito sobre as expectativas dos educandos quanto ao ensino que buscam no IFSC. Assim, não podemos ignorar a necessidade de analisar a formação ofertada pelo Instituto Federal de Santa Catarina, campus São Miguel do Oeste (IFSC/SMO), levando em conta as concepções dos educandos e as expectativas que eles têm em relação ao mundo do trabalho, para dar uma 
resposta satisfatória aos desafios que a Educação Profissional enfrenta para construir na prática uma relação consistente e crítica entre educação e trabalho.

Nessa perspectiva, o presente estudo foi instigado tanto pelo interesse dos autores em se aprofundar nos estudos sobre a temática "trabalho e educação" quanto pela percepção da maneira como os estudantes das fases finais dos cursos de graduação do IFSC manifestam constantemente suas expectativas relacionadas à conclusão do curso e seus anseios quanto à inserção no mercado de trabalho. A partir dessas motivações, entre outras inquietações dos autores, na busca por respostas foram definidos os seguintes objetivos: 1) analisar o perfil dos estudantes cursantes da 8 8 $^{\text {a }}$ fase do Curso de Agronomia do IFSC/SMO, em 2019; 2) refletir sobre a formação ofertada aos educandos no referido curso e sobre as expectativas e necessidades em relação ao mercado de trabalho; 3) investigar quais as limitações e contribuições do curso de Agronomia do IFSC/SMO quanto à relação trabalho e educação; e 4) analisar a concepção de alunos do Curso de Agronomia para identificar os significados e o valor atribuído ao trabalho, por esses estudantes.

Para atingir esses objetivos e obter os dados necessários ao desenvolvimento da pesquisa, adotamos uma metodologia que envolveu a aplicação de questionários. Esse instrumento foi constituído com questões previamente estruturadas que ao serem respondidas, e analisadas as respostas, revelam elementos importantes sobre o perfil dos estudantes, suas expectativas quanto à formação oferecida pelo IFSC, suas concepções de trabalho e as relações entre educação e sociedade, entre outros aspectos. Os dados coletados foram interpretados com base em categorias elencadas a partir dos dados empíricos e de estudos teóricos realizados. Muitos elementos que surgiram, a partir dos dados investigados, fazem parte do diálogo entre teoria e prática, buscando indicativos que qualificam a ação pedagógica realizada na instituição. Assim, a fundamentação teórica toma por base autores como Saviani (2007, 2008, 2009), Frigotto (2005, 2012), Kuenzer (2001), Antunes (2000), Lessa (2012), Antunes e Alves (2004), entre outros, que contribuíram para dar suporte à análise dos dados encontrados.

Além das ponderações acima que constituem a introdução do artigo (1), apresenta-se, na sequência, o referencial teórico da pesquisa (2) e também a metodologia adotada para a realização do estudo (3), descrevendo os instrumentos e os procedimentos utilizados para a coleta e organização dos dados. E, depois 
disso, a descrição e análise dos dados (4) em que os resultados da pesquisa realizada são apresentados. E, por último, as considerações finais (6), retomando os objetivos e os pressupostos de pesquisa em sua relação com uma síntese dos principais resultados encontrados, para o fechamento do texto.

\section{Desafios contemporâneos na relação trabalho-educação: revisitando conceitos para a fundamentação teórica da pesquisa}

As discussões sobre a relação trabalho-educação no âmbito da formação acadêmica tornam-se relevantes quando a temática é abordada na complexidade que the é própria. Ao realizar o trabalho educativo, supõe-se como essencial o desafio de planejar um processo formativo que permita dar bases teóricas e práticas consistentes para que o futuro profissional possa enfrentar a realidade complexa que constitui o mundo do trabalho.

Saviani (2007) conceitua "o trabalho" como uma ação especificamente humana, pois somente os seres humanos trabalham; e através da racionalidade a produção das condições dadas pelo trabalho se fazem presentes na vida da humanidade. Por sua vez, Dentz (2011, p. 93) explica que "o ser dos homens é social e se constitui em suas bases originárias pelo trabalho, ou seja, o homem necessita produzir sua própria existência, e a produz em sociedade". Com isso, o autor ressalta que a sociedade precede às nossas ações, mas que ao mesmo tempo a sociedade existe como um produto das ações humanas. E então considera que "diante dos imperativos e condicionamentos presentes na sociedade - e, em particular, na educação - a cada momento a análise crítica pode revelar que o futuro se encontra aberto a novas possibilidades. O desafio é encontrar o caminho" (DENTZ, 2011, p. 94).

Essa capacidade de pensar, planejar e transformar desafia os seres humanos constantemente, no sentido da sua emancipação das condições meramente existenciais para a produção de uma vida em sociedade; assim, as transformações da natureza, com vistas a produção das condições objetivas e subjetivas de nossa existência, conduzem à reflexão e à ação em torno do valor do trabalho enquanto práxis especificamente humana. Nesse sentido, Cortella (2009, p. 41) afirma que 


\begin{abstract}
essa ação transformadora consciente é exclusiva do ser humano e a chamamos trabalho ou práxis; é consequência de um agir intencional que tem por finalidade a alteração da realidade de modo a moldá-la às nossas carências e inventar o ambiente humano. $O$ trabalho é, assim, o instrumento da intervenção do humano sobre o mundo e de sua apropriação (ação de tornar próprio) por nós.
\end{abstract}

Contudo, não nascemos sabendo, e nem sabendo trabalhar; e isso sugere considerar um processo contínuo de apropriação do mundo, mas também a necessidade de nos apropriarmos de nós mesmos enquanto seres em construção. É nesse sentido que se impõe a centralidade do trabalho e da educação. Ou seja, as relações entre a esfera da produção material e a do trabalho educativo, considerando o valor que adquirem nas sociedades complexas, são essenciais para a humanidade e para seu próprio desenvolvimento. Ora, fomos educados com base na ideia de que "o trabalho edifica o homem", mas, como se dá cotidianamente a valorização do trabalho, do cuidado com a qualidade de vida, com a educação e com a dignidade humana?

A emancipação social precisa que esforços sejam feitos no sentido da transformação da realidade em benefício de todos os indivíduos e grupos sociais, respeitando as diferenças que os constituem enquanto sujeitos históricos. Sabe-se, entretanto, que o significado do trabalho não é o mesmo nas diferentes culturas. Porém, os desafios impostos ao mundo do trabalho, nas relações sociais determinadas pelo capitalismo, têm provocado a necessidade constante de redução do tempo livre, ampliando a visão de que é preciso trabalhar mais e mais, sem considerar o cuidado com as consequências negativas para a qualidade de vida e das relações humanas. Ou seja, se não questionarmos os sentidos do trabalho, corremos o risco da perda do seu sentido original, à medida que se converte em fator de alienação.

Antunes e Alves (2004) enfatizam que o valor do trabalho precisa ser considerado, ou seja, não como elemento de alienação, mas como fator relevante para a estruturação da sociedade. E com isso destacam a necessidade de que a análise teórica avalie as condições reais em que as diferentes formas de trabalho são realizadas, nos contextos sociais e históricos. Assim, ao verificar o cenário em que ocorre a expansão do trabalho precarizado, parcial, informal, temporário e terceirizado (ANTUNES; ALVES, 2004), a formação acadêmica precisa investigar os 
anseios e as necessidades do mundo do trabalho para se apropriar criticamente dessa realidade e pensar o perfil dos profissionais que pretende formar.

A sociedade contemporânea impõe constantemente inúmeros desafios para a qualificação profissional. Com a modernização constante e acelerada, os conhecimentos impostos como verdades são refutados e novos saberes tomam corpo quando as práticas são revistas e aperfeiçoadas constantemente, ou seja, não há como a formação acadêmica desconsiderar o contexto social e econômico no qual vivemos. Além disso, é necessário acrescentar, conforme Antunes e Alves (2004, p. 338), que "as mutações organizacionais, tecnológicas e de gestão também afetaram fortemente o mundo do trabalho nos serviços, que cada vez mais se submetem à racionalidade do capital e à lógica dos mercados”. Assim,

para se compreender a nova forma de ser do trabalho, a classe trabalhadora hoje, é preciso partir de uma concepção ampliada de trabalho. Ela compreende a totalidade dos assalariados, homens e mulheres que vivem da sua força de trabalho, não se restringindo aos trabalhadores manuais diretos, incorporando também a totalidade do trabalho social, a totalidade do trabalhador coletivo que vende sua força de trabalho como mercadoria em troca de salário (ANTUNES; ALVES 2004, p. 342).

A função social da educação exige considerar nas discussões, portanto, o mundo do trabalho e as condições dos trabalhadores em sentido amplo. Antunes e Alves (2004) ressaltam que a "classe trabalhadora" compreende a totalidade dos assalariados, homens e mulheres que vivem da sua força de trabalho, ou seja, os despossuídos dos meios de produção. Nesse sentido, quando consideramos a concepção ampliada do trabalho, destaca-se, por um lado, a necessidade de refletir sobre a condição das mulheres, dos negros e dos jovens no mercado de trabalho, sobre a situação das pessoas que são excluídas em razão da faixa etária e dos desempregados em geral, e, por outro lado, de se contrapor às legislações que flexibilizam e precarizam as condições dos trabalhadores, independentemente dos fatores identitários, e também de avaliar os novos modelos de trabalho oferecidos pelo mundo tecnológico. Ou seja, a análise do trabalho que se faz pelas vias da concreticidade histórica é aquela que se pauta pelas relações reais existentes de trabalho. Assim,

é preciso fazer uma distinção entre o trabalho como relação criadora do homem com a natureza, o trabalho como atividade de autodesenvolvimento físico, material, cultural, social, político, estético, o trabalho como manifestação de vida, e o trabalho nas suas formas históricas de sujeição, 
de servidão ou de escravidão, ou do trabalho moderno, assalariado, alienado, forma específica de produção da existência no capitalismo. Há relações de trabalho concreto que atrofiam o corpo e a mente, trabalhos que embrutecem, que aniquilam, fragmentam, parcializam 0 trabalhador. (FRIGOTTO, CIAVATTA, RAMOS, 2005, p. 26).

As condições contemporâneas do mundo do trabalho, marcadas por contradições, sinalizam desafios quanto ao papel das instituições de ensino na qualificação dos profissionais, na perspectiva de uma formação comprometida com a capacidade dos agentes de identificar os processos de alienação e estranhamento no mundo social, enquanto consciência crítica que mobiliza para a ação individual e coletiva dos sujeitos que reivindicam o que é seu por direito, a participação nas conquistas sociais materiais e intelectuais que são fruto do trabalho. Contudo, ao considerar a educação como fator de empoderamento social, precisamos lembrar que

a alienação/estranhamento é ainda mais intensa nos estratos precarizados da força humana de trabalho, que vivenciam as condições mais desprovidas de direitos e em condições de instabilidade cotidiana, dada pelo trabalho part-time, temporário e precarizado (ANTUNES; ALVES 2004, p. 348).

Frente a essa realidade, é importante resgatar o compromisso social da educação, tanto em relação aos excluídos do mundo do trabalho quanto aos que se encontram desprovidos de seus direitos fundamentais, pois, tanto os inseridos no mercado quanto os excluídos dele sofrem as consequências impostas pelos interesses dominantes no modo capitalista de produção e exploração do trabalho.

Partindo da ideia do compromisso da educação com o mundo do trabalho, verifica-se a importância da formação integral dos educandos que, além de profissionais comprometidos com o exercício da profissão, precisa formar cidadãos capazes de identificar teoricamente e realizar na prática valores primordiais que possam garantir a vida em sociedade com dignidade. De fato, vivemos em tempos de incertezas em que a qualificação profissional está sendo cada vez mais cobrada, mas o exercício da profissão não está garantido e nem as condições dignas de trabalho, dadas as tendências em curso de precarização e retirada de direitos dos trabalhadores. Contexto esse que desperta nos educandos da educação profissional a sensação de insegurança, no sentido de não se sentirem prontos para atender as expectativas do mundo do trabalho.

"Formar para o mercado de trabalho" tornou-se uma assertiva que tem reduzido a noção de formação profissional a uma mera instrumentalização, 
que visa, de um lado, servir como incremento para aumentar as chances de ingresso no mercado de trabalho - e, nesse caso, o que mais importa é a titulação em si - e, por outro, garantir uma formação técnica comportamental que responda aos imperativos mais imediatos do setor produtivo em detrimento de uma compreensão alargada do exercício profissional (SILVA, 2008, p. 54).

Contudo, muito além de simplesmente formar profissionais para o mercado, Antunes e Alves (2004) alertam para o compromisso da educação em desenvolver nos educandos a capacidade crítica e reflexiva de analisar a conjuntura dos grandes problemas contemporâneos. Formar profissionais para o mundo do trabalho significa pensar a formação de sujeitos preocupados com a identidade da profissão e com a dignidade humana, resgatando a historicidade do conceito de "trabalho" e discutindo sobre os desafios do mundo contemporâneo no que tange às relações educação e trabalho. Conforme os autores,

\begin{abstract}
à educação superior cabe a tarefa de organizar a cultura superior como forma de possibilitar que participem plenamente da vida cultural, em sua manifestação mais elaborada, todos os membros da sociedade, independentemente do tipo de atividade profissional a que se dediquem. Assim, além do ensino superior destinado a formar profissionais de nível universitário (a imensa gama de profissionais liberais e de cientistas e tecnólogos de diferentes matizes), formula-se a exigência da organização da cultura superior com o objetivo de possibilitar a toda a população a difusão e discussão dos grandes problemas que afetam 0 homem contemporâneo (ANTUNES; ALVES 2004, p. 161).
\end{abstract}

O papel da educação é ampliar os horizontes em sua missão de trabalhar os conhecimentos científicos. Muito além do domínio das técnicas, será essencial refletir sobre o domínio teórico e prático dos saberes no processo produtivo. A formação acadêmica precisa romper com a passividade intelectual. Conforme Saviani (2007), deve-se evitar que os universitários caiam no academicismo, para que seja possível recuperar os vínculos e as relações existentes entre trabalho manual e intelectual. Nesse sentido, ter o trabalho como princípio educativo, conforme Ciavatta (2005) retoma de Gramsci (1981, p. 144), significa "superar a dicotomia trabalho manual/trabalho intelectual" para "incorporar a dimensão intelectual ao trabalho produtivo e formar jovens e adultos trabalhadores capazes de atuar como dirigentes e cidadãos, não apenas como governados".

Ao tratar do tema trabalho e educação, cabe sempre considerar a realidade dos estudantes, a maneira como e para que se ensina, e também as rupturas que ainda precisam ser feitas em vista de uma formação integral dos sujeitos, capazes de intervir na vida em sociedade. Muitos são os desafios postos 
para a formação profissional: a titulação para o exercício da profissão, a qualificação permanente e a formação atualizada são algumas das exigências para aumentar as suas possibilidades de se manter no mercado ou desenvolver a empregabilidade. Porém, o maior desafio talvez seja pensar uma educação que não seja passiva e subserviente ao mercado, e construir estratégias contra-hegemônicas de educação, que possam ser transformadoras das práticas pedagógicas e assim contribuir para a superação efetiva das pedagogias conformistas na educação profissional dos trabalhadores que conduzem a passividade e a aceitação das condições impostas.

Nesse sentido, adotar a perspectiva do trabalho como princípio educativo exige considerar a formação dos seres humanos e suas relações com o mundo social em que a educação está inserida. Frigotto (2005) contribui nessa discussão quando diz que a relação com o trabalho deve ser mediada com o objetivo de cumprir os imperativos de justiça social e de acompanhamento das transformações técnico-científicas do mundo do trabalho. Por sua vez, Saviani (2007, p. 160) destaca que

aprender a ler, escrever e contar, e dominar os rudimentos das ciências naturais e das ciências sociais constituem pré-requisitos para compreender o mundo em que se vive, inclusive para entender a própria incorporação pelo trabalho dos conhecimentos científicos no âmbito da vida e da sociedade.

De fato, com o desenvolvimento histórico-social o mundo tem se tornado cada vez mais complexo, de maneira que a educação formal emerge como uma exigência social indispensável para situar os indivíduos na realidade em que vivem. Assim, conforme Arroyo (2013, p. 143), "o objetivo da pedagogia moderna não tem sido outro senão entender os processos complexos de humanização e ajudar os educandos nessa trajetória". E o autor também explica:

o que diferencia a pedagogia moderna é ser "humanista" ou estar a serviço de um projeto - processo de autoconstrução como humanos e não estar a serviço de um projeto pré-definido de fora. Educar nada mais é que humanizar, caminhar para a emancipação, a autonomia responsável, a subjetividade moral, ética. Nosso objetivo tem sido as relações entre trabalho - educação - humanização - emancipação (ARROYO, 2013, p. 143-144).

Portanto, a concepção da "educação como capital humano" se manifesta como uma concepção reducionista da prática educativa circunscrita unicamente às necessidades do mercado, ao passo que o compromisso social da educação com os 
princípios humanísticos, com a ética e com a formação de sujeitos emancipados vai muito além da esfera mercadológica. Todavia, a vida profissional dos estudantes, conforme a visão tradicional de educação, em geral se deixa orientar por outros valores, mais imediatistas e focados na empregabilidade, enquanto elemento de apropriação do trabalho dos aprendizes, muitas vezes o que é esperado pelas famílias. Frente a isso, o compromisso social da educação não pode se restringir aos limites internos dos muros da escola. $E$ as discussões em torno do conceito de trabalho, enquanto princípio educativo, sinalizam para a importância de se partir da realidade dos educandos e compreender sua historicidade, conhecer suas origens e trajetórias, para situar suas expectativas quanto à profissão.

A valorização do pensar, a superação da prática pela prática, o desenvolvimento da intelectualidade, da capacidade de reflexão, da possibilidade de despertar nos sujeitos a consciência de sua própria existência e das possibilidades de intervir na sociedade e transformar a realidade, a apropriação consciente do conhecimento e o domínio das exigências básicas necessárias ao trabalhador profissionalizado são elementos essenciais à educação profissional. Contudo, a discussão sobre a educação e o trabalho e seus reflexos na vida profissional dos educandos não se esgota, devido à amplitude do tema e particularmente considerando os diversos sentidos atribuídos tanto ao trabalho quanto à educação.

Antunes (2000) destaca, ao se perguntar sobre os sentidos do trabalho na sociedade atual, que para existir uma vida cheia de sentido fora do trabalho é necessária uma vida dotada de sentido dentro do trabalho. É essa também uma questão fundamental à educação que se volta para o trabalho, constituir-se como uma educação cheia de sentido tanto para as questões que dizem respeito ao mundo do trabalho quanto para as demais questões da vida em sentido amplo. Amplitude esta concebida por Saviani (2008, p. 13) ao considerar o trabalho educativo como "o ato de produzir, direta e indiretamente, em cada indivíduo singular, a humanidade que é produzida histórica e coletivamente pelo conjunto dos homens".

\section{Procedimentos metodológicos da investigação}

Os conceitos revisitados e apresentados na fundamentação teórica foram identificados mediante pesquisa bibliográfica. Por outro lado, os dados empíricos 
foram obtidos por meio da pesquisa de campo, realizada para identificar as concepções dos estudantes do $8^{\circ}$ período do Curso de Agronomia do IFSC/SMO, relacionadas à educação e ao trabalho. A pesquisa de campo consistiu na aplicação de um questionário previamente estruturado aos estudantes, contendo questões abertas e fechadas.

Conforme Guebur e seus colaboradores (2016, p. 362), “o questionário pode possuir perguntas fechadas ou abertas e ainda a combinação dos dois tipos" para que sejam utilizadas não apenas as quantidades, mas a qualidade das respostas obtidas. De modo geral, as questões abertas do questionário aplicado são sobre "o quê", "porquê" e "como" da relação trabalho-educação, quanto aos sentidos que adquire no caso em estudo. Por outro lado, as questões fechadas se prestam à obtenção de informações quantificáveis que permitiram caracterizar o perfil geral dos sujeitos investigados. Desse modo, a pesquisa se caracteriza pela abordagem quantitativa e também qualitativa dos dados encontrados.

Para Minayo (2001), a pesquisa qualitativa trabalha com o universo de significados, motivos, aspirações, crenças, valores e atitudes, que corresponde ao espaço mais profundo das relações, dos processos e dos fenômenos, que não podem ser reduzidos à operacionalização de variáveis. A pesquisa realizada também se define por seu caráter exploratório, pois, conforme a autora, este tipo de pesquisa almeja proporcionar maior familiaridade com o problema, com vistas a torná-lo mais explícito ou a construir hipóteses explicativas. Nesse sentido, a pesquisa explorou uma série de questões que relacionam educação e trabalho no âmbito da formação realizada no Curso de Agronomia do IFSC/SMO.

Entre as questões principais, podemos destacar: Qual o perfil dos educandos do $8^{\circ}$ período do Curso de Agronomia? De que realidade são oriundos? Como percebem a formação que estão recebendo no curso? Quais os avanços e as limitações dessa formação? Quais expectativas dos estudantes em relação ao mercado de trabalho? Quantos já atuam na área e buscam a especialização e quantos almejam ingressar na profissão? Qual a concepção que possuem do termo "trabalho"? Como percebem a relação existente entre o processo de ensino e o exercício da profissão, ou seja, quanto à relação trabalho e educação?

A partir dessas questões e orientações metodológicas, as respostas foram obtidas e, em seguida, foram sistematizadas e analisadas, sendo os dados 
agrupados em categorias. Minayo (2001) afirma que as categorias são empregadas para se estabelecer classificações e para agrupar elementos, ideias ou expressões em torno de um conceito capaz de abranger um significado. Dessa maneira, tais resultados analisados e categorizados serão apresentados a seguir.

\section{Resultados e discussão}

O estudo realizado, conforme destacamos, teve como base as discussões sobre o mundo do trabalho, as relações que permeiam o tema, oportunizando o aprofundamento teórico e reflexivo sobre os desafios com os quais a educação se defronta no que envolve a temática. Assim, elementos teóricos foram mobilizados para pensar o problema que instigou o desenvolvimento do estudo, e na busca por respostas, conforme descrito na metodologia, realizamos pesquisa de campo, aplicando questionários a 34 estudantes do Curso de Agronomia do IFSC/SMO.

O Curso superior de Bacharelado em Agronomia do IFSC/SMO foi implantado no ano de 2016, sendo o primeiro na área a ser ofertado de forma pública e gratuita na região. Assim, ao ser criado, tornou-se uma oportunidade para a sequência nos estudos, em nível de graduação, tanto para os egressos dos cursos técnicos e integrados do IFSC/SMO quanto aos demais alunos concluintes do Ensino Médio de outras escolas da região e também para muitos que veem na oferta uma oportunidade para cursar a universidade, em busca de profissionalização.

\section{Breve diagnóstico sobre o perfil dos estudantes, sujeitos da investigação}

A partir das informações coletadas com os 34 estudantes do 8 período do Curso de Agronomia do IFSC/SMO, constatou-se que 21 tem idade entre 20 a 25 anos, o que significa que a maior parte deles ingressou no curso superior logo após a conclusão do Ensino Médio. Ao passo que 8 estudantes se encontram na faixa etária de 26 a 30 anos. Enquanto que os outros 5 têm mais de 31 anos de idade. Com base nessas informações, podemos evidenciar o perfil bastante jovem do grupo de alunos, mas também verificar que houve a procura pelo retorno aos estudos por parte de indivíduos com mais idade.

Outra questão a ser observada para um diagnóstico do perfil da turma refere-se à representatividade de gênero na constituição do grupo. Sobre isso, de modo geral, cabe ressaltar que mesmo com tantas conquistas no mundo moderno, 
ainda existem profissões que são consideradas como trabalho para homens, e outras como trabalho específico para mulheres. As transformações na sociedade contemporânea ainda não conseguiram equalizar a igualdade entre os gêneros. $E$ essa questão cultural, em se tratando do tema educação e trabalho, possui forte influência nas relações sociais e, particularmente, nas questões relacionadas à escolha da profissão e da formação universitária.

Nesse aspecto, quanto aos estudantes do Curso de Agronomia, conforme os dados da pesquisa demonstram, o grupo masculino é significativamente maior do que o feminino. Em números, a proporção é $79 \%$ masculino contra $21 \%$ do grupo feminino. Configuram-se, portanto, as características de um curso voltado majoritariamente ao público masculino, o que não foge à regra no cenário nacional. $E$, consequentemente, condicionam a entrada no mercado de trabalho, que no caso da agronomia será também destacadamente masculina, reforçando uma injustificada divisão sexual do trabalho. Esses dados, se inseridos no contexto geral, confirmam a constatação de Antunes e Alves (2004) quanto à condição das mulheres no mercado de trabalho. Segundo os autores,

\begin{abstract}
muitos estudos têm apontado que, na nova divisão sexual do trabalho, as atividades de concepção ou aquelas de capital intensivo são realizadas predominantemente pelos homens, ao passo que aquelas de maior trabalho intensivo, frequentemente com menores níveis de qualificação, são preferencialmente destinadas às mulheres trabalhadoras (ANTUNES; ALVES, 2004, p. 338).
\end{abstract}

Outra característica importante a ser destacada é que dos 34 estudantes participantes da pesquisa, 30 deles cursaram a educação básica em escolas públicas. Quando questionados sobre a forma de ingresso, 16 estudantes informaram ter sido através do vestibular ${ }^{3}$. Constatou-se também, ainda em relação à formação anterior dos estudantes, que $68 \%$ deles já tinham realizado o curso técnico de nível médio em ciências agrárias, conforme se observa no gráfico 1 . A escolha pelo curso de Agronomia, portanto, foi feita pelo interesse em permanecer na área, o que reforça a necessidade de especialização e a busca por uma formação qualificada desde o ensino médio, que possa ser então aprimorada no Ensino Superior, dando sequência ao itinerário formativo.

\footnotetext{
3 Nas demais turmas do curso de Agronomia da instituição, em que o acesso vem sendo exclusivamente via SISU (Sistema de Seleção Unificada), o impacto das transferências e evasões tem sido uma preocupação quanto ao número de alunos que permanecem nos cursos.
} 
Gráfico 1. Distribuição dos estudantes por formação anterior no ensino técnico.

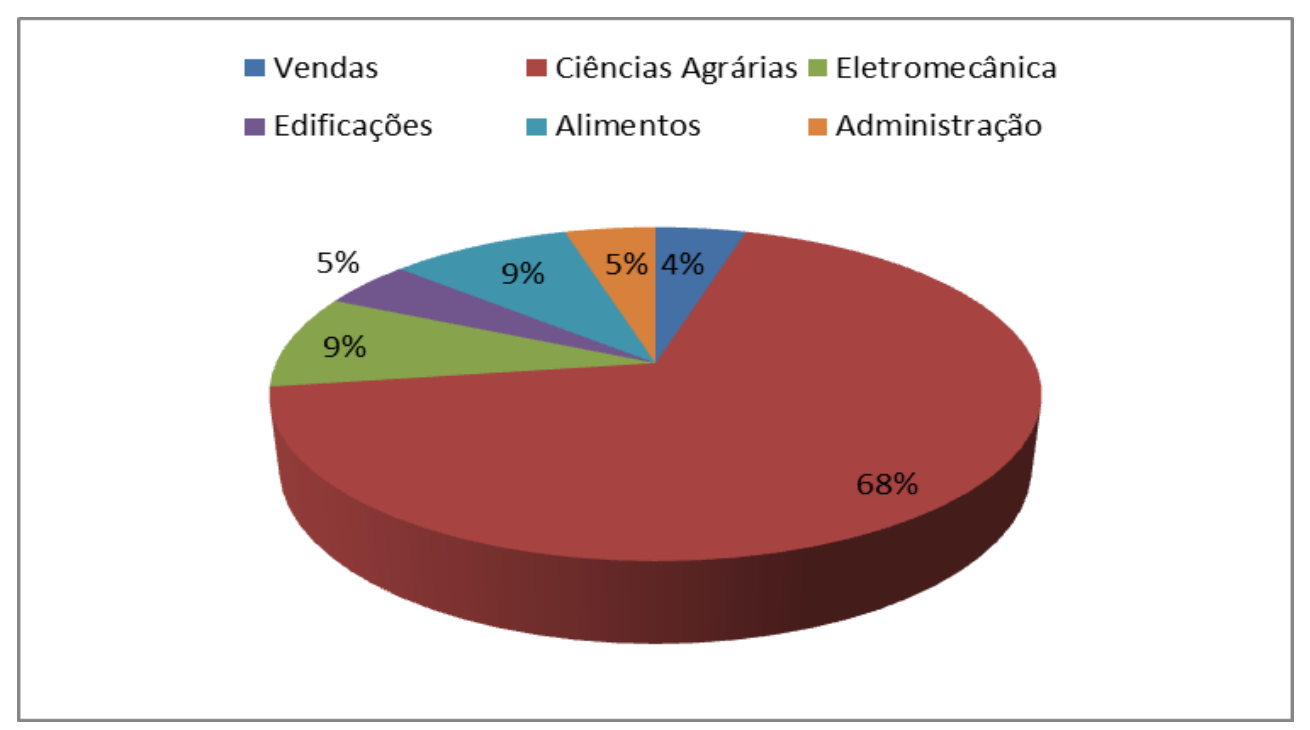

Fonte: Os autores, a partir de informações coletadas em dezembro de 2019.

O interesse pela área também pode ser evidenciado pela constatação de que 26 dos respondentes (76,5\%) afirmaram que o curso de Agronomia foi a sua primeira opção. Essa resposta está associada ao fato de ser a empregabilidade uma das grandes preocupações dos alunos durante o curso. A condição ideal deveria ser o foco na formação acadêmica de qualidade e que a inserção no mercado de trabalho pudesse ser o resultado imediato desses esforços despendidos pelos educandos e educadores durante os anos dedicados ao curso, porém, a realidade nos apresenta a condição da maioria dos estudantes que precisam trabalhar e estudar, conciliando as duas atividades ao mesmo tempo como estudantes/trabalhadores ${ }^{4}$.

A preocupação dos estudantes quanto ao aperfeiçoamento na área de Agronomia também está associada ao fato de que 14 deles trabalham na agricultura. Sendo filhos de agricultores, trabalham nas lavouras com seus pais e são incentivados a buscar qualificação para o desempenho das atividades agrícolas que as famílias realizam. Na verdade, somando com outros 6 jovens urbanos, são 22 ao todo que moram com seus pais e não possuem filhos (ou seja, 64,70 \% deles). Mas,

\footnotetext{
${ }^{4}$ Um exemplo forte é dado pela necessidade crescente de qualificar-se melhor e preparar-se mais para conseguir trabalho. Parte importante do "tempo livre" dos trabalhadores está crescentemente voltada para adquirir "empregabilidade", palavra-fetiche que o capital usa para transferir aos trabalhadores as necessidades de sua qualificação (ANTUNES; ALVES, 2004, p. 339).
} 
em geral, todos são originários da região, de São Miguel do Oeste ou dos municípios vizinhos, de modo que não precisaram mudar de cidade para estudar.

Quando questionados sobre se participam de algum projeto de ensino, pesquisa, extensão, enquanto bolsista ou estagiário, ou em intercâmbios ofertados pelo IFSC, constatou-se, pela análise das respostas, a preocupação dos estudantes em participar das atividades propostas pela instituição, que no caso se referem a projetos que também proporcionam acesso diferenciado aos conhecimentos científicos da área. Assim, através da participação em projetos de pesquisa, extensão, estágios, entre outros, buscam aumentar a sua qualificação teórica e prática, para enfrentar o mundo do trabalho com mais segurança.

\section{Da relação educação profissional e mundo do trabalho}

Historicamente as discussões sobre educação e mundo do trabalho foram marcadas por visões conservadoras. O papel da escola na formação dos educandos está ainda muito ligado à instrumentalização ${ }^{5}$. Contudo, pensar a formação numa perspectiva sociológica contra-hegemônica implica em considerar o trabalho como princípio educativo, então, a instituição de ensino se distancia das práticas reprodutivistas e se aproxima da educação transformadora, com seu compromisso em desenvolver o pensamento crítico. Segundo Luckesi (2003, p. 69), "a difusão de conteúdos é primordial, não conteúdos abstratos, mas vivos, concretos e, portanto, indissociáveis das realidades sociais".

A qualificação para o trabalho ocorre juntamente com a formação de universitários capazes de protagonizar mudanças nos aspectos políticos, econômicos e sociais. Nessa perspectiva, educação não é simplesmente reprodução, mas é vista como um ato intencional, planejado, aliando teoria e prática, que qualifica os estudantes para atuar no mercado de trabalho e na vida em sociedade de maneira crítica e responsável.

\footnotetext{
5 "A escola, no capitalismo monopolista, sob a hegemonia burguesa, especialmente após a Segunda Guerra Mundial, vem se estruturando com vistas a formar, tanto em sentido amplo como em sentido estrito, um intelectual urbano de novo tipo, que apresenta como características principais o aumento da capacitação técnica necessária à reprodução ampliada das relações capitalistas de produção e uma nova capacitação burguesa, com vistas a "humanizar" as relações de exploração e de dominação burguesas, enquanto possibilidades históricas concretas" (NEVES; SANT'ANNA, 2005, p. 29).
} 
O ensino profissional ofertado pelo IFSC precisa fazer sentido para os estudantes/trabalhadores que têm muitas vezes a sobrevivência como preocupação imediata. Na verificação das respostas dos alunos, quanto à questão sobre o nível de satisfação que possuem em relação ao trabalho que desenvolvem, alguns indicativos sobre suas percepções podem ser observados nas seguintes respostas:

\begin{abstract}
Preciso de dinheiro e o trabalho é rentável. / Não tenho escolha, se não trabalhar, não pago as contas. / Trabalho pesado, e em parceria com o estudo se torna cansativo. / Trabalho cansativo, sem valorização. / É o que paga as contas e bota comida na casa. / Mesmo com dificuldades, tenho orgulho de pagar as minhas contas sozinho, mesmo trabalhando meio período. / Nasci para ser agricultor. / Gosto muito da área e trabalho com a sucessão familiar. (ESTUDANTES RESPONDENTES) ${ }^{6}$
\end{abstract}

As respostas dadas pelos estudantes demonstram a necessidade do trabalho voltado para o sustento, como provimento da renda (conforme será destacado a seguir, no Gráfico 2, com a sistematização das respostas obtidas quanto aos diferentes significados atribuídos ao trabalho pelos estudantes pesquisados), de maneira que a formação intelectual, o tempo para os estudos e a preocupação com a qualidade da formação acadêmica estariam em segundo plano. $\mathrm{E}$, sobretudo considerando os estudantes mais jovens, constata-se a característica de uma herança familiar na qual os conceitos formados pelos pais são repassados aos filhos, marcados pela necessidade do trabalho como essencial para a vida.

No entanto, há que se evidenciar que a formação intelectual demanda tempo e dedicação aos estudos, fato que muitas vezes não se torna 0 mais relevante, pois a procura pela vaga no mercado de trabalho, um emprego, é a prioridade essencial. Levando em conta as condições dos estudantes e das famílias, cabe considerar as desigualdades que interferem nas esperanças subjetivas relacionadas à educação recebida e nas oportunidades futuras objetivas de trabalho ${ }^{7}$ que a formação profissional de fato consegue proporcionar.

Portanto, tomando por base as discussões sobre o trabalho como princípio educativo, vale ressaltar o compromisso da educação em desvendar as condições alienadas que almejam tão somente a desenfreada exploração do

\footnotetext{
${ }^{6}$ As respostas dos estudantes são apresentadas de maneira agrupada pelo significado que as mesmas expressaram e, portanto, não foram identificadas separadamente.

${ }^{7}$ Conforme Kuenzer (2001, p. 34), "o ingresso no mercado de trabalho faz parte das necessidades do trabalhador e, portanto, a escola não deverá ignorá-las desde que o faça na perspectiva [...] de promover o acesso ao saber científico e tecnológico que permita ao trabalhador inserir-se, participar e usufruir dos benefícios do processo produtivo".
} 
trabalho pelo capital. Saviani (2007) contribui com essa reflexão sobre a necessidade de uma formação em nível superior comprometida com os valores da inclusão na vida cultural, só assim os estudantes serão capazes de perceber como o capital se apropria da vida humana, de modo que o trabalhador não consegue se ver como ser humano dotado de valores, necessidades e interesses que estão para além da esfera produtiva.

Para Saviani (2011, p. 118), "estamos em uma nova época histórica, uma nova ordem global, em que as velhas formas não estão mortas, mas as novas ainda não estão inteiramente formadas". Nesse contexto, as exigências do mundo contemporâneo impactam também pela necessidade de considerar a articulação da prática com os conhecimentos teóricos, ou seja, a especialização universitária precisa articular formação intelectual e trabalho produtivo. É preciso, portanto, repensar as concepções de educação para incorporar o significado do trabalho.

No estudo realizado, os estudantes foram questionados sobre o significado da palavra "trabalho". As respostas foram categorizadas pela interpretação das informações descritas pelos estudantes/respondentes que foram organizadas por suas semelhanças e diferenças de significado, conforme se apresenta no gráfico a seguir.

Gráfico 2. Quantificação das respostas quanto aos significados do "trabalho".

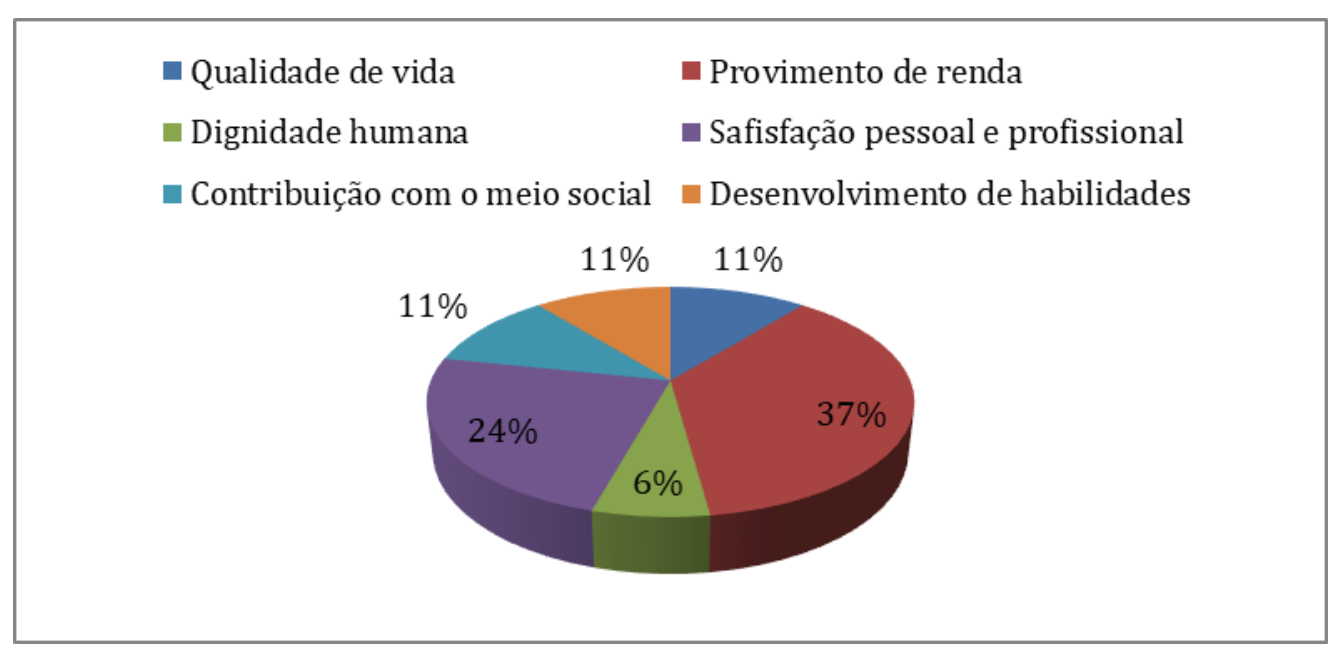

Fonte: Os autores, a partir de informações coletadas em dezembro de 2019.

A análise das respostas dadas pelos estudantes sobre o significado de "trabalho" teve a categoria "provimento de renda" como a mais destacada. De fato, o processo de ruptura de um pensamento capitalista, no qual a preocupação central é 
o valor que se dá ao dinheiro, não é uma tarefa simples, são desafios dados aos processos educativos que também participam da elaboração social dos significados do trabalho. No entanto, há sim indicativos daqueles que conseguem perceber a importância do trabalho em seu sentido mais amplo, considerando aspectos como a qualidade de vida, a dignidade humana e a contribuição com o meio social.

A "satisfação pessoal e profissional" e "o desenvolvimento de habilidades" também foram significados identificados. De fato, o significado do trabalho como o que permite a realização profissional e o desenvolvimento de novas habilidades adquire valor imprescindível para a construção da identidade profissional dos indivíduos. E, nesse sentido, quando os estudantes do curso de Agronomia foram questionados sobre como se sentem em relação ao exercício da profissão de agrônomo, $68 \%$ afirmaram se sentirem preparados para o mundo do trabalho. E dentre as justificativas dadas podemos destacar os seguintes fragmentos das respostas descritivas: Sim, porque tenho conhecimento básico que vai me ajudar no mercado de trabalho. / Tenho conhecimento porque sempre lidei com a agricultura. I Tenho experiência e conhecimento técnico. (ESTUDANTES RESPONDENTES).

Grande parte dos estudantes já possuem experiências anteriores quanto aos trabalhos da agricultura, muitos trabalham cotidianamente nas propriedades da família, conforme destacamos, alguns atuam em trabalhos indiretos na área, e são poucos aqueles que dependeram do curso para realizar as primeiras aproximações com o meio agrícola. Considerando tal realidade, vale ressaltar a importância dos saberes anteriores, a valorização da realidade trazida pelos estudantes precisa ser considerada, a articulação entre a teoria e a prática nos processos de aprendizagem estimula a compreensão dos conceitos científicos. Assim os estudantes podem contribuir significativamente no processo de construção do conhecimento com suas experiências práticas.

Aos estudantes, perguntamos também se, na opinião deles, a realidade do mundo do trabalho foi contemplada nas unidades curriculares do curso que eles frequentam. A análise das respostas aponta que para $50 \%$ deles, as relações com o mundo do trabalho e o exercício da profissão foram realizadas de maneira satisfatória no conjunto das disciplinas. Enquanto a outra metade do grupo considera que $o$ assunto foi parcialmente contemplado. Sobre isso, vejamos alguns fragmentos 
de respostas dadas pelos alunos que apontam para certa limitação institucional nesse aspecto:

\begin{abstract}
Para um curso de Agronomia é fundamental que tenha conhecimento da parte prática. / Vejo que existe uma distância grande da realidade, quanto mais estudamos mais nos distanciamos da realidade do que acontece na prática. / A falta de experiência do professor é nítida, sempre explicando pela teoria. / A aplicabilidade de certos conteúdos é difícil. / Poderia existir maior ligação com a prática. (ESTUDANTES RESPONDENTES).
\end{abstract}

As respostas dadas pelos educandos demonstram a preocupação com 0 saber prático, ou seja, sinalizam para a necessidade de dominar os elementos da prática em vista do exercício da profissão. Contudo, urge salientar as falas dos estudantes que expressam a consciência da importância de que a teoria e a prática estejam de fato interligadas nos componentes do curso. Ou seja, o fazer pelo fazer não basta. Cabe ao educando o domínio das técnicas, mas também dos saberes teóricos que fundamentam as práticas e os fazeres da Agronomia. As respostas também ressaltam que os estudantes, em sua grande maioria, possuem relação com a agricultura, ou atuam diretamente, ou suas famílias possuem vínculos com o campo. Portanto, por possuírem saberes oriundos do próprio cotidiano, exigem que os conhecimentos teóricos contenham elementos suficientes para que sejam traduzidos em saberes práticos, aplicáveis à realidade que eles conhecem.

Ao refletir sobre o conceito de trabalho como princípio educativo, as dimensões intelectuais e laborais, ou seja, teoria e prática são princípios fundamentais. Para que aconteça a ruptura de práticas até então condizentes com a educação unilateral, a ação docente não pode ser uma mera transmissão de conhecimentos, mas sim, um ato intencional, uma ação instrumentalizadora, capaz de contribuir com a apropriação dos conceitos e métodos científicos em benefício de um projeto de educação omnilateral ${ }^{8}$, no qual se destaca o compromisso com 0 desenvolvimento pleno do ser humano e com a formação de sujeitos comprometidos politicamente com a construção de uma sociedade mais justa.

\footnotetext{
8 Nesse sentido, Frigotto (2012, p. 270- 271) alerta que "a tarefa do desenvolvimento humano omnilateral e dos processos educativos que a ele se articulam direciona-se num sentido antagônico ao ideário neoliberal. $\mathrm{O}$ desafio é, pois, a partir das desigualdades que são dadas pela realidade social, desenvolver processos pedagógicos que garantam, ao final do processo educativo, o acesso efetivamente democrático ao conhecimento na sua mais elevada universalidade. Não se trata de tarefa fácil e nem que se realize plenamente no interior das relações sociais capitalistas. Esta, todavia, é a tarefa para todos aqueles que buscam abolir estas relações sociais".
} 
Nesse sentido, o Projeto Pedagógico do Curso de Bacharelado em Agronomia do IFSC/SMO prevê, quanto ao perfil dos estudantes egressos, que eles:

sejam críticos, éticos e responsáveis profissionalmente e socialmente; tenham conhecimento das tecnologias, bases científicas e fatores de produção necessários para atingir a melhor eficiência técnica e econômica, utilizando preceitos ecológicos e racionais; utilizem conhecimentos técnicos fundamentados numa visão sistêmica e humanística, com lógica e criatividade, mantendo o pensamento reflexivo a serviço da sustentabilidade econômica, social e espacial; promovam o desenvolvimento social e econômico de forma mais justa e humana no meio em que vivem; sejam engajados e tenham conhecimento de política agrícola, de forma a garantir melhores condições para a vida e permanência no campo; percebam as transformações sociais e seu respectivo impacto no mundo do trabalho, atuando de forma proativa em situações emergentes (PPC - CURSO AGRONOMIA, 2017, p. 11).

Como pode ser observado, considerando as competências que se deseja dos estudantes formados, alguns elementos se destacam: conhecimento, bases científicas, transformações sociais, eficiência técnica e econômica, consciência ecológica e mundo do trabalho. A formação integral dos sujeitos considerando aspectos teóricos e práticos também está presente nas prioridades do curso. No projeto do curso consta a preocupação com a formação voltada para a instrumentalização técnica, dando as bases científicas para a atuação no mundo do trabalho. Então, quando se observa as afirmações dos educandos quanto ao distanciamento do curso em relação à parte prática, podemos perceber certo distanciamento entre aquilo que se deseja e a realidade vivida.

A educação possui um papel relevante em contribuir para a reflexão sobre o mundo do trabalho. Além da qualificação para o exercício da profissão, é primordial se repensar os ideais da formação para o trabalho como princípio pedagógico/didático comprometido com a produção dos saberes e com a vida em sociedade. Os conhecimentos primevos e as experiências anteriores contribuem para a compreensão dos conhecimentos teóricos, assim, os saberes construídos em sala de aula fazem parte da relação necessária na práxis pedagógica. A necessidade da transposição didática fica evidenciada como uma exigência ao exercício da profissão docente.

Recentemente, professores universitários começaram a se conscientizar de que seu papel de docente do ensino superior, como o exercício de qualquer profissão, exige capacitação própria e específica que não se restringe a ter um diploma de bacharel, de mestre ou doutor, ou apenas o exercício de uma profissão. Exige isso tudo e competência pedagógica, pois ele é um 
educador, alguém que tem a missão de colaborar eficientemente para que seus alunos aprendam (MASSETO, 2012. p. 15).

A mediação entre teoria e prática faz parte dos desafios da formação docente, a articulação dos saberes científicos com a realidade se fazem essenciais quando a transposição didática se preocupa com a aprendizagem significativa. $\mathrm{O}$ domínio das técnicas amplia os limites da sala de aula, e a produção dos saberes deve considerar os conhecimentos teóricos e práticos capazes de instrumentalizar os sujeitos para transformar a realidade através da sua inserção e atuação diferenciada no mundo do trabalho. É o que se deseja.

\section{Considerações finais}

De acordo com os dados apresentados, muitas são as expectativas dos jovens estudantes do curso de Agronomia e, considerando que estão na reta final do curso, verifica-se que há uma grande preocupação quanto à sua formação e à inserção no mercado de trabalho. Conforme se constatou, os estudantes já possuem uma forte relação com a área do curso, seja por meio do trabalho que exercem, seja por atividades afins ou pelas formações anteriores. A grande maioria reside no município de São Miguel do Oeste, ou em cidades próximas, facilitando o acesso aos estudos no IFSC, porém, preocupam-se com a oferta de trabalho nessa região. Muitos também pensam em permanecer atuando na propriedade da família, após o término do curso, e outros em buscar uma vaga na área, em empresas.

Sobre a qualidade do curso de Agronomia, afirmam ter um bom nível de satisfação reconhecendo significativamente a formação que realizam, no entanto, sinalizam para a necessidade de mais prática no curso. Em geral, estão preocupados com o mundo do trabalho, no sentido de ir além da teoria e ter a prática presente também quanto aos conteúdos trabalhados em sala de aula. Assim, por exemplo, avaliam que os componentes curriculares deveriam proporcionar mais momentos em que a prática dos conteúdos fosse vivenciada.

Quanto aos sentidos atribuídos à palavra "trabalho", notou-se que as suas percepções estão marcadas por perspectivas capitalistas, por exemplo, ao significar trabalho apenas como uma forma de "ganhar dinheiro". Contudo, dadas as condições econômicas de muitos estudantes, esse significado também está atrelado ao "provimento da renda". Por outro lado, observou-se também a preocupação de 
muitos em ter o trabalho como forma de satisfação pessoal e profissional. Todavia, considerando uma análise mais sociológica, poucos percebem a relação existente entre o processo de ensino e a formação para o exercício da profissão na perspectiva do trabalho não alienado, pois verifica-se a percepção mais técnica e pouco comprometida com as possíveis transformações sociais necessárias para melhorar as condições dos trabalhadores.

Por tudo o que foi apresentado, o estudo realizado sinaliza para a importância da reflexão constante sobre o exercício da docência, na perspectiva de um ensino comprometido com práxis que consiga articular a teoria e a prática na construção do conhecimento profissional. Dessa forma, a temática do trabalho como princípio educativo possui muita relevância nesse contexto; embora não seja uma discussão nova, as mudanças na sociedade moderna apresentam novos desafios para a educação. Assim, o tema não se esgota. A análise sobre a percepção dos alunos do curso de Agronomia do IFSC, campus São Miguel do Oeste, aponta para a necessidade de considerar 0 trabalho como referência na organização pedagógica, ou seja, como princípio educativo. O desafio está posto. Trata-se de pensar a prática pedagógica de maneira comprometida com a formação de sujeitos capazes de estabelecer relações éticas na vida em sociedade e no mundo do trabalho, resgatando a historicidade do conceito de trabalho para pensar a identidade profissional dos educandos, sem ignorar os desafios contemporâneos, quanto à relação educação e trabalho, para além da vida simplesmente produtiva.

\section{Referências Bibliográficas}

ANTUNES, Ricardo. Os sentidos do trabalho: ensaio sobre a afirmação e a negação do trabalho. São Paulo: Boitempo, 2000.

ANTUNES, Ricardo; ALVES, Giovanni. As mutações no mundo do trabalho na era da mundialização do capital. Educação \& Sociedade, Campinas, vol. 25, n. 87, p. 335-351, maio/ago. 2004.2 Disponível em <https://www.cedes.unicamp.br/publicacoes/edicao/132>. Acesso em 22 ago. 2020.

ARROYO, Miguel. Trabalho - educação e teoria pedagógica. In: FRIGOTTO, Gaudêncio (org.). Educação e crise do trabalho: perspectivas de final de século. 12. Ed. Petrópolis, RJ: Vozes. 2013.

CIAVATTA, Maria. A formação integrada à escola e o trabalho como lugares de memória e de identidade. Trabalho Necessário, v. 3, n. 3, p. 1-20, 2005. Disponível 
em <https://periodicos.uff.br/trabalhonecessario/article/view/6122>. Acesso em 17 abr. 2020.

CORTELLA, Mario Sergio. A escola e o conhecimento: fundamentos epistemológicos e políticos. 13. Ed. São Paulo: Cortez, 2009.

DENTZ, Volmir von. Uma falácia nas Teorias da Educação: reducionismo epistemológico e negação da ontologia. In.: SILVA, Neide de Melo Aguiar; RAUSCH, Rita Buzzi (Orgs.). Pesquisa em Educação: pressupostos epistemológicos e dinâmicas de investigação. Blumenau: Edifurb, 2011.

FRIGOTTO, Gaudêncio. Concepções e mudanças no mundo do trabalho e o Ensino Médio. In: FRIGOTTO, Gaudêncio; CIAVATTA, Maria; RAMOS, Marise (Orgs.). Ensino Médio Integrado: concepções e contradições. São Paulo: Cortez, 2005.

FRIGOTTO, Gaudêncio. Educação omnilateral. In: CALDART, Roseli Salete; PEREIRA, Isabel; ALENTEJANO, Paulo; FRIGOTTO, Gaudêncio (Orgs.) Dicionário da educação do campo. São Paulo: Expressão Popular, 2012.

GUEBUR, Josimara Adriana; SANTOS, Juliana Caroline; MELO, Maria Carolina de Lara; KONDO, Petrine Ariana de Souza; LOZZA, Silvia luan. A contribuição do uso das tecnologias para o processo de aprendizagem nos anos iniciais. 2016.

Disponível em <https://memorialtcccadernograduacao.fae.edu/cadernotcc/article/download/153/54> . Acesso em 12 dez. 2019.

IFSC. Plano de Desenvolvimento Institucional - PDI 2015-2019. 2014. Disponível em <http://pdi.ifsc.edu.br/download/facao-download-do-pdi-2015-2019/>. Acesso em 16 mar. 2020.

KUENZER, Acácia Zeneida. Ensino de 2o grau - o trabalho como princípio educativo. 4. Ed. São Paulo: Cortez, 2001.

LESSA, Sérgio. Mundo dos Homens: trabalho e ser social. 3. ed. São Paulo: Instituto Lukács, 2012.

LUCKESI, Cipriano Carlos. Filosofia da Educação. 19r. São Paulo: Cortez, 2003.

MANFREDI, Silvia Maria. Educação profissional no Brasil. São Paulo: Cortez, 2002.

MASSETO, Marcos Tarciso. Competência Pedagógica do Professor Universitário. 2. Ed. São Paulo: Summus, 2012.

MINAYO, Maria Cecília de Souza (Org.). Pesquisa Social. Teoria, método e criatividade. 18ª Ed. Petrópolis: Vozes, 2001.

NEVES, Lúcia Maria Wanderley; SANTANA, Ronaldo. Introdução: Gramsci, o Estado educador e a nova pedagogia da hegemonia. In.: NEVES, Lúcia Maria 
Wanderley (Org.). A nova pedagogia da hegemonia: estratégias do capital para educar o consenso. São Paulo: Xamã, 2005.

Projeto Pedagógico do Curso de Agronomia (PPC). Instituto Federal de Santa Catarina - IFSC, 2017.

SAVIANI, Dermeval. Trabalho e educação: fundamentos ontológicos e históricos. Revista Brasileira de Educação. 2007, vol. 12, n. 34, pp. 152-165. <https://www.scielo.br/scielo.php?script=sci_arttext\&pid=S1413-

24782007000100012>. Acesso em 16 jun. 2020.

SAVIANI, Dermeval. Pedagogia Histórico-Crítica: primeiras aproximações. 8. Ed. Campinas, SP: Autores Associados, 2008.

SAVIANI, Dermeval. Escola e democracia. 41. Ed. Campinas, SP: Autores Associados, 2009.

SAVIANI, Dermeval. Educação em diálogo. Campinas, SP: Autores Associados, 2011.

SILVA, Mariléia Maria da. Formar para o mercado de trabalho: a retórica da competência e competitividade nos cursos de graduação. Boletim Técnico do SENAC, Rio de Janeiro (RJ), v. 34, n. 2, p. 45-55, maio 2008.

\section{Idianes Tereza Mascarelo \\ São Miguel do Oeste, Santa Catarina, Brasil}

Possui graduação em Pedagogia- Habilitação em Supervisão Educacional pela Universidade Comunitária Regional de Chapecó (1998), Especialização em Supervisão Escolar pela Universidade de Passo Fundo (2000), Pós-graduação em Atualização em Educação pela Universidade de Passo Fundo (2002), Pósgraduação em Docência no Ensino Superior- Universidade Comunitária Regional de Chapecó (2015), Especialização em Docência para a Educação Profissional e Tecnológica (2020) e Mestrado em Educação pela Universidade de Passo Fundo (2005). Atuou como professora da Universidade Comunitária da Região de Chapecó (UNOCHAPECÒ), Doutoranda em Educação pela UNISC. Atua como servidora pública federal no cargo de Pedagoga no Instituto Federal de Santa Catarina - IFSC, Campus São Miguel do Oeste. Atua nos seguintes temas: práticas pedagógicas, formação de professores, educação profissional, organização do ensino educação e trabalho.

E-mail: idianes.mascarelo@ifsc.edu.br

Link do Lattes: http://lattes.cnpq.br/5721478261198810 


\section{Volmir von Dentz}

São José, Santa Catarina, Brasil

Possui graduação em Filosofia pela Fundação Educacional de Brusque (FEBE), mestrado em Educação pela Universidade Regional de Blumenau (FURB) e doutorado em Educação pela Universidade Estadual de Campinas (UNICAMP). É professor do Instituto Federal de Educação, Ciência e Tecnológica de Santa Catarina (IFSC) e membro do Grupo de Pesquisa Educação, Cultura e Sociedade (ESCULTURA-IFSC). É integrante do Laboratório de Pesquisas Sociológicas Pierre Bourdieu (LAPSB) e do Grupo de Pesquisa Ensino e Formação de Educadores em Santa Catarina (GPEFESC - PPGE/UFSC). Tem experiência na área de Filosofia e Educação, atuando principalmente nos seguintes temas: Filosofia, Educação, Teorias da Educação, Filosofia da Educação, Epistemologia da Pesquisa em Educação, Teorias Pós-Críticas, Ontologia Crítica, Epistemologia, Ética, Sociologia da Educação, Filosofia da Tecnologia e Educação Profissional e Tecnológica.

E-mail: volmir@ifsc.edu.br

Link do Lattes: http://lattes.cnpq.br/7132058525179906

\section{Recebimento: $28 / 08 / 2020$}

Aprovação: 25/03/2021

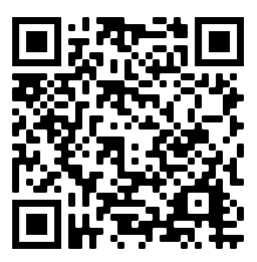

\section{Q. Code}

\section{Editores-Responsáveis}

Dr. Enéas de Araújo Arrais Neto, Universidade Federal do Ceará, UFC, Ceará, Brasil Dr. Sebastien Pesce, Universidade de Orléans, França 